\title{
Impact of Psycho-Social Intervention in Patient with GBS in Neurological Rehabilitation Set Up: A Case Report
}

\section{Arun M and BP Nirmala*}

Department of Psychiatric Social Work and Consultant in Neurological Rehabilitation, NIMHANS, India

*Corresponding Author: BP Nirmala, Department of Psychiatric Social Work and Consultant in Neurological Rehabilitation, NIMHANS, India.
Received: March 24, 2020

Published: April 28, 2020

(C) All rights are reserved by Arun $\mathbf{M}$ and BP Nirmala.

\begin{abstract}
The current case report describes the psycho-social assessment carried out with a person diagnosed with Guillain-Barre syndrome. Psycho-social assessment sheet which is developed for assessing psycho-social factors of patients with neurological disorder and hospital anxiety and depression scale has been used in the case report. This report also focuses on the caregiver's issues and the associated interventions. The common psycho-social intervention which was used in this case has alleviated patient's emotional distress and helped her go through rehabilitation process effectively. Findings of this case study support the fact that medical management complimented with psychosocial intervention could help the patient and family members deal with social and psychological dysfunctions effectively.
\end{abstract}

Keywords: Gullian Barre Syndrome; Rehabilitation; Psychosocial Intervention

\section{Introduction}

Neurological disorders can create increased mortality rate as well as morbidity rate due its chronicity, limited therapeutic option and non-availability of adequate treatment. Along with psychosocial issues stigma among community members and inadequate number of neurologist also contribute to this lacunae [1]. Gullian Barre Syndrome is rare neurological condition which affects peripheral nerves due to person's immune system. This neurological disorder affects all population irrespective of their gender. Most of the patients have significant issues in self-esteem and are likely to develop moderate to severe depression and anxiety about their health condition. People with GBS have profound impact on psycho-social functioning and quality of life [2,3]. There is a lack of substantial studies especially from the psycho-social intervention perspective with respect to Guillain-Barre syndrome.

\section{Case Summary}

Socio-demographic profile

The indexed client is 22 year old female, single, Christian, completed B.com, working as an accountant in private company since 6 month, currently staying with parents, hailing from lower socioeconomic status, from urban Bangalore Karnataka.

\section{Source of information}

The information had been collected from the patient herself and her parents.

\section{Reason for referral}

The case had been referred to psychiatric social worker for effective psycho-social management and rehabilitation services.

\section{Assessments}

- Psychosocial assessment performa: It includes sociodemographic profile of the patient, social domains and psychological components.

- Hospital anxiety and depression scale: The Hospital Anxiety and Depression scale (HAD) is developed by Zigmond and Snaith. It is a brief questionnaire (containing 14 items) and was originally designed to detect emotional disturbances in non-psychiatric patients treated at hospital clinics. The scale measures both anxiety and depression on two separate subscales, each containing 7 items. HAD has been used to detect anxiety and depression in psychiatric patients ( $2-5)$, as well as in medical patients $(6-13)[4,5]$. 


\begin{tabular}{|l|c|c|c|c|c|}
\hline Sl. no & Scales & \multicolumn{2}{|c|}{ Pre-rehabilitation } & \multicolumn{2}{c|}{ Post -rehabilitation } \\
\hline \multirow{2}{*}{1.} & \multirow{2}{*}{ HAD } & Anxiety & Depression & Anxiety & Depression \\
\cline { 3 - 6 } & & 11 & 14 & $03^{*}$ & 0 \\
\hline
\end{tabular}

*Anxious about the recurrence of episode.

\section{Brief clinical history}

Ms. M was working as an accountant in a private company when the first episode occurred July 2018. When a colleague tried to pull the patient back, she fell down and found it difficult to lift herself up but did not experience any pain or disturbance then. She began to complain of bilateral muscle pain and weakness in lower limbs the next day and thus was limping. Her sensory integrity was reported intact. After her initial investigation at a government hospital, she was prescribed medication. Patient reported an increase in her lower limb weakness and initiation of pain in upper limbs. At this point, family consulted at a private hospital where the diagnosis made was effect of psychological distress on body. Since there was no improvement patient consulted neurology department which in turn referred to Neuro-Rehabilitation.

Premorbid personality: Well adjusted.

Family history

Her father is 53 years old, works as a rickshaw driver, found to be alcohol dependent since 20 years (accepted by family) and has diabetes mellitus (untreated). Patient's mother is 44 year old and she is a housewife.

\section{Family dynamics}

Boundary and decision making (particularly patient related) among the subsystem was open and democratic in nature. Father played multiple roles on the functional and nominal front and that was accepted by other members. Role clarity, role differentiation, both verbal-non-Verbal pattern of communication, positive reinforcement (major source - Father), positive problem solving skills was found to be present in the family. Primary Social support was present in family however secondary and tertiary support was found to be inadequate on emotional domain.

\section{Personal history}

Patient was born in a consanguineous union with normal milestones of developmental milestones clearly. Patient studied English medium and has been found to have an average performance until her graduation. She started working in a private company as an accountant for past one year with a monthly income of $12,000 /$ and has good relationship with her colleagues. Her menstruation cycle began at the age of 14 and has been regular since inception. She does not follow a particular schedule in her life but has interest in watching television, chatting with friends and cooking.
Psycho-social assessment findings (rehabilitation perspective)

During admission, patient was dependent for all activities of daily living because of weakness in upper and lower limbs. Financial issues were present in the family due to multiple hospitalizations. Inadequate knowledge about the illness and rehabilitation process among patient as well as parents was present. There was significant emotional distress in parents. Biological functioning of patient was inadequate and poor social interaction was present in earlier days of hospitalization. Social support in the family was minimal. Father was the only breadwinner in the family; the long term hospital stay affected their livelihood. Caregiver burden reported secondary financial issues, physical issues of mother. Parents were expecting that patient should achieve pre-morbid level of functionality and were following medical model of illness. Guilt feeling in patient was reported during assessment, alcohol abuse in father and poor physical condition of mother were aggravated patient's distress. Patient's obesity was an interrupting factor for providing adequate rehabilitation care. Depressive cognition was present during intake.

\section{Psycho-social intervention}

The psycho-social intervention in this case is explaining about illness, supportive counseling, activity schedule, recreational group, peer supportive group, caregivers supportive group, dance movement therapy, pre-discharge counseling.

\begin{tabular}{|c|c|}
\hline Nature of intervention & Number of session \\
\hline Individual session & 5 \\
\hline Peer group (GBS) & 3 \\
\hline Recreational group & 2 \\
\hline Care givers support group & 4 \\
\hline
\end{tabular}

*Anxious about the recurrence of episode.

\section{Supportive counseling}

Supportive Counseling' was adopted to facilitate optimal adjustment, particularly in situations of ongoing stress such as chronic physical illness. The therapeutic relationship between client and therapist facilitated enhanced coping skills, reduce feeling of guilt. In session common supportive techniques like clarification, confrontation, interpretation, praise, reassurance, encouragement, advice, teaching anticipatory guidance, reducing and preventing anxiety were incorporated to reduce the emotional distress for better rehabilitation.

\section{Psycho-education}

Initial sessions with patient and her family focused on educating them about the nature of illness, its course, prognosis, symptoms and also management using the Information model of psycho-ed- 
ucation. Significance of attending occupational and physiotherapy was also discussed in the session. Emotional aspects of the patient were also addressed in the session

Structuring daily schedule

\begin{tabular}{|c|c|}
\hline Therapies & Timings \\
\hline Occupational therapy & 9.30 am to 10.30 \\
\hline Physiotherapy & 11 am to $12 \mathrm{pm}$ \\
\hline
\end{tabular}

Apart from the therapy hours, patient found her hospital time unproductive as she mostly slept through or used her mobile phone. To tackle this concern, the idea is to engage her into peripheral services such as library, computers, reading newspapers and interact with other patients. Administering these activities had functional limitation due to her illness. However, each activity was scheduled to be supervised by the therapist and used as intervention using pleasure principle and mastery principles.

\section{Predischarge counseling}

During discharge period patient was briefly educated about the illness especially course of illness since it is an episodic nature of illness. Continuation of therapies at home, regular medication, importance of following new diet, increase physical autonomy and reduce the dependency, importance of taking initiatives in carrying out activities, following a structure on daily basis was highly recommended. Warning symptoms to look out for, importance of follow up was discussed with the patient and her family to ensure the treatment adherence.

\section{Recreational group}

Patient was included in the recreational group therapy to channelize energy productively which focused on activities and games, all activities were goal oriented which fostered social and selfidentity as well.

\section{Peer supportive group}

Peers provide assistance and support to increase skills and knowledge that will overcome interpersonal, family, social, financial, inter-agency and other disability-related challenges.

- Adjustment with dysfunction and disability,

- Grief and loss issues,

- Management of physical, psychological, economic issues.

\section{Post discharge plans}

During session patient came up with her concerns and how she manages her issues during hospitalization. The sessions went up to 45 minutes which was on Wednesday, each week.
Caregiver's supportive group: Both mother and father attended the supportive group each Wednesday

- The challenges and issues of caregivers

- $\quad$ Caregivers burden

- $\quad$ Stress management

- Improving treatment adherence.

Group used to happen up to 45 minutes. Both parents had expressed their concerns especially paucity of financial support from their family members and concerns about daughters future, marriage and recurrence of episode. Severe emotional distress was present in the father because patient was affectionate towards him compared to her mother.

\section{Discussion}

Lack of knowledge about the illness among the patients and the family members can increase the emotional distress and fear especially worries related to prognosis, bowel and bladder issues, motor weakness and pain. Educating about the illness can take the edge off their emotional distress as well as fear [6]. Long term health related concerns are inability to perform in social activities, sustain occupation among other emotional stresses [7]. Psychiatric condition is an associated impact among person with GuillainBarre Syndrome, in that depression is the common disorder along with anxiety disorder but brief psychosis is also reported as a reaction to the illness [8]. Financial burden is a troubling factor of person with neurological disability which would be a concern of family members during hospitalization which makes illness like Guillain-Barre Syndrome a long term financial concern. It is noted that financial aspect is the only dis-satisfactory element in care along with information for the caregivers [9]. Care giver burden is an associated factor of treatment of neurological disability due to other common issues; it can be financial, physical or psychological. It is important to effectively deal with care givers burden by stakeholders related to the treatment [10]. Family members also needs to be educated about regular follow up, importance of family support, regular medication, life style modification, importance of work etc [11]. According to the bio-psychosocial model, there is a significant relationship between person's genetic contribution, psychological aspects and social as well as cultural background on one's experience of health and illness. The biological contribution can be any infection, physical trauma, problems in nutrition or hormonal changes which could lead to the abnormality in health. Once the abnormality or deformity strikes, it is reflected in the psychological and emotional make-up of the individual through emotional distress, negative thinking, low self-control etc. The social aspects like economic issues, burden in caregivers, poor social support can also be a contributing factor to the distress and anxiety. This theory emphasize that presence of single factor would not be the reason, it can be the interplay or dynamics of these three factors [12]. 
In this case study we could find the changes in the caregivers and patient since the knowledge on illness was provided. Post assessment also found changes in depression and anxiety in patient.

\section{Conclusion}

The intervention which was carried out in this case can be considered as a feasibility approach for person with Guillain-Barre syndrome. The interventions applied in this particular case are not common and have been/can be used for other diagnosis.

\section{Bibliography}

1. Math SB., et al. "The rights of persons with disability bill, 2014: implications for neurological disability". Annals of Indian Academy of Neurology 19.1 (2016): S28-S33.

2. Khan F. "Rehabilitation in Guillian Barre syndrome". Australian Family Physician 33.12 (2004): 1013-1017.

3. Merkies IS and Kieseier BC. "Fatigue, pain, anxiety and depression in Guillain-barré syndrome and chronic inflammatory demyelinating polyradiculoneuropathy". European Neurology 75.3-4 (2016): 199-206.

4. Lisspers J., et al. "Hospital Anxiety and Depression Scale (HAD): some psychometric data for a Swedish sample". Acta Psychiatrica Scandinavica 96.4 (1997): 281-286.

5. Bjelland I., et al. "The validity of the Hospital Anxiety and Depression Scale: an updated literature review". Journal of Psychosomatic Research 52.2 (2002): 69-77.

6. Sulton LL. "A multidisciplinary care approach to Guillain-Barré syndrome". Dimensions of Critical Care Nursing 20.1 (2001): 16-22.

7. Khan F., et al. "Factors associated with long-term functional outcomes and psychological sequelae in Guillain-Barre syndrome". Journal of Neurology 257.12 (2010): 2024-2031.

8. Weiss H., et al. "Psychotic symptoms and emotional distress in patients with Guillain-Barré syndrome". European Neurology 47.2 (2002): 74-78.

9. Forsberg A., et al. "Use of healthcare, patient satisfaction and burden of care in Guillain-Barre syndrome". Journal of Rehabilitation Medicine 38.4 (2006): 230-236.

10. Boaventura LC., et al. "Assessment of the burden of adult wheelchair-bound patients with neurological disabilities on the caregiver". Ciencia and Saude Coletiva 21.10 (2016): 31933202.
11. Raju B and Reddy K. "Are counseling services necessary for the surgical patients and their family members during hospitalization?" Journal of Neurosciences in Rural Practice 8.1 (2017): 114-117.

12. Havelka M., et al. "Biopsychosocial model-the integrated approach to health and disease". Collegium Antropologicum 33.1 (2009): 303-310.

\section{Assets from publication with us}

- Prompt Acknowledgement after receiving the article

- Thorough Double blinded peer review

- Rapid Publication

- Issue of Publication Certificate

- High visibility of your Published work

Website: www.actascientific.com/

Submit Article: www.actascientific.com/submission.php Emaill us: editor@actascientific.com

Contact us: +919182824667 